\title{
Predation of Ostrinia nubilalis (Lepidoptera: Crambidae) Eggs in Sweet Corn by Generalist Predators and the Impact of Alternative Foods
}

\author{
FRED R. MUSSER ${ }^{1}$ AND ANTHONY M. SHELTON \\ Department of Entomology, Cornell University, New York State Agricultural Experiment Station, \\ 630 W. North Street, Geneva, New York 14456
}

Environ. Entomol. 32(5): 1131-1138 (2003)

\begin{abstract}
Generalist predators are common in most agricultural cropping systems. However, pest control from these predators is often overlooked as a component of integrated pest management (IPM) because the extent of predation is generally unknown and difficult to assess. In western New York sweet corn (Zea mays L.), the primary predators are Orius insidiosus (Say), Coleomegilla maculata (DeGeer), and Harmonia axyridis (Pallas). European corn borer [Ostrinia nubilalis (Hübner) ] is the primary insect pest. The objectives of this study were to compare O. nubilalis egg predation rates for these three species and to understand how egg predation by these predators is affected by the availability of alternative food. Laboratory data indicate that all three predators feed on $O$. nubilalis eggs. C. maculata consumed more eggs than H. axyridis or O. insidiosus. Immatures of C. maculata and $O$. insidiosus readily completed development on a diet of $O$. nubilalis eggs, but $H$. axyridis larvae could not complete development on this diet. The presence of corn leaf aphids [Rhopalosiphum maidis (Fitch) ] and corn pollen reduced egg predation per insect for some stage of all species. The reduction in O. nubilalis egg predation associated with the presence of aphids was confirmed in field cage studies and was similar among the coccinellid populations tested. Field studies comparing aphids, predator populations, and $O$. nubilalis egg predation show that reduced egg predation per insect more than offsets the higher populations encountered when aphids and pollen are numerous, resulting in less biological control of $O$. nubilalis when alternative foods are available.
\end{abstract}

KEY WORDS Coleomegilla maculata, Harmonia axyridis, Orius insidiosus, predator, alternative food

GENERALIST PREDATORS ARE present in most agricultural systems, yet the contributions of these predators have been largely overlooked in commercial pest management because the extent of predation is unknown, unpredictable, or difficult to assess. Surveys in sweet corn (Zea mays L.) fields in the northeastern United States have historically found that the primary insect predators are Coleomegilla maculata (DeGeer) (Coleoptera: Coccinellidae) and Orius insidiosus (Say) (Heteroptera: Anthocoridae) (Whitman 1975, Andow and Risch 1985, Coll and Bottrell 1992, Hoffmann et al. 1997). However, the recent arrival of Harmonia axyridis (Pallas) (Coleoptera: Coccinellidae) (Coderre et al. 1995, Wheeler and Stoops 1996) introduced a new predator into the sweet corn system.

In 1998-2001, the most numerous predators in sweet corn in western New York were $O$. insidiosus, $C$. maculata, and H. axyridis (Musser 2003). All three of these predators are highly polyphagous and omnivorous, feeding on many types of insects as well as plants (Putnam 1964, Corey et al. 1988, Hironori and Katsuhiro 1997). In sweet corn, many potential food sources

\footnotetext{
${ }^{1}$ E-mail: frml@cornell.edu.
}

(aphids, mites, thrips, pollen, lepidopteran eggs, and small larvae) for these predators are frequently available in varying abundance, making the extent of predation on any single prey type difficult to predict.

The most important pests in sweet corn in North America are the lepidopteran species Ostrinia nubilalis (Hübner) (Lepidoptera: Crambidae), Spodoptera frugiperda (J. E. Smith) (Lepidoptera: Noctuidae), and Helicoverpa zea (Boddie) (Lepidoptera: Noctuidae) (Flood et al. 1995). In northern areas of the United States, O. nubilalis is the main pest throughout the growing season, while the other Lepidoptera are primarily late-season pests. Overall $O$. nubilalis egg predation in the region has been recorded through use of sentinel eggs or exclusion cages at levels ranging from 2 to 50\% (Andow and Risch 1985, Hudon and LeRoux 1986, Phoofolo et al. 2001). Given this wide range of predation levels and the arrival of $H$. axyridis since these studies, more studies on biological control from the current predator complex must be conducted. In particular, factors influencing predation rates need to be better understood so that natural predation can be included as a pest management factor. Two major factors known to influence the re- 
Table 1. Consumption of $O$. nubilalis eggs \pm SEM, larval development rate \pm SEM and mortality for C. maculata, H. axyridis and O.insidiosus at $20^{\circ}$ and $27^{\circ} \mathrm{C}$

\begin{tabular}{|c|c|c|c|c|c|c|c|c|c|c|}
\hline \multirow[b]{2}{*}{ Insect $^{a}$} & \multicolumn{5}{|c|}{$20^{\circ} \mathrm{C}$} & \multicolumn{5}{|c|}{$27^{\circ} \mathrm{C}$} \\
\hline & $\begin{array}{l}\text { Insects/ } \\
\text { rep }\end{array}$ & Reps & $\begin{array}{c}\text { ECB eggs } \\
\text { eaten/ } \\
\text { day/insect }^{b}\end{array}$ & $\begin{array}{c}\text { Longevity } \\
\text { (d) }\end{array}$ & $\begin{array}{c}\% \\
\text { mortality }\end{array}$ & $\begin{array}{l}\text { Insects/ } \\
\text { rep }\end{array}$ & Reps & $\begin{array}{c}\text { ECB eggs } \\
\text { eaten/ } \\
\text { day/insect }^{b}\end{array}$ & $\begin{array}{c}\text { Longevity } \\
\text { (d) }\end{array}$ & $\begin{array}{c}\% \\
\text { mortality }\end{array}$ \\
\hline C. maculata adult & 1.0 & 34 & $6.2 \pm 0.8$ & $18.0 \pm 1.5$ & na & 1.0 & 35 & $12.1 \pm 1.5$ & $8.6 \pm 0.5$ & na \\
\hline C. maculata early instar ${ }^{c}$ & 1.0 & 23 & $1.0 \pm 0.3$ & $10.5 \pm 0.7$ & 52 & 1.0 & 26 & $4.4 \pm 1.1$ & $5.0 \pm 0.3$ & 42 \\
\hline C. maculata late instar ${ }^{d}$ & 1.0 & 11 & $14.5 \pm 1.4$ & $11.2 \pm 0.6$ & 27 & 1.0 & 19 & $12.3 \pm 1.8$ & $4.1 \pm 0.3$ & 84 \\
\hline H. axyridis adult & 1.0 & 41 & $2.4 \pm 0.3$ & $11.0 \pm 1.0$ & na & 1.0 & 43 & $3.7 \pm 0.7$ & $6.8 \pm 0.7$ & na \\
\hline H. axyridis early instar ${ }^{c}$ & 1.0 & 8 & $0.0 \pm 0.0$ & $3.0 \pm 0.0$ & 100 & 1.0 & 8 & $0.3 \pm 0.3$ & $3.0 \pm 0.0$ & 100 \\
\hline H. axyridis late instar ${ }^{d}$ & 1.0 & 18 & $5.9 \pm 1.5$ & $5.2 \pm 0.8$ & $61^{e}$ & 1.0 & 20 & $7.4 \pm 1.8$ & $3.6 \pm 0.5$ & $25^{e}$ \\
\hline O. insidiosus adult & 1.4 & 5 & $1.9 \pm 0.2$ & $16.9 \pm 3.2$ & na & 2.8 & 8 & $2.1 \pm 0.2$ & $12.8 \pm 1.3$ & na \\
\hline O. insidiosus nymph & 4.5 & 12 & $1.1 \pm 0.2$ & $8.9 \pm 0.7$ & 73 & 5.0 & 12 & $1.6 \pm 0.2$ & $6.4 \pm 0.6$ & 45 \\
\hline
\end{tabular}

Statistical comparisons between $20^{\circ} \mathrm{C}$ and $27^{\circ} \mathrm{C}$ and between coccinellids and $O$. insidiosus not appropriate. na, not applicable.

${ }^{a}$ All late instar H. axyridis were collected in the field as late instars. All other insects were from laboratory colonies.

${ }^{b} \mathrm{O}$. nubilalis egg mass consumption by coccinellids converted to eggs by multiplying by 15 , the mean number of $O$. nubilalis eggs per egg mass.

${ }^{c}$ First and second instars.

${ }^{d}$ Third and fourth instars.

${ }^{e}$ All $H$. axyridis larvae that pupated did so within the first two days after collection from the field.

sponse of generalist predators to prey are temperature (Giroux et al. 1995, Elliott et al. 2000) and the quantity, quality, and visibility of alternative foods (Ables et al. 1978, Andow and Risch 1985, Corey et al. 1988, Hazzard and Ferro 1991, Cottrell and Yeargan 1998, Eubanks and Denno 2000, Roger et al. 2001). Most existing studies have examined only a single predator, making the impact of alternative foods on overall predation rates in cropping systems with multiple predator species difficult to assess. The objectives of our studies were to evaluate $O$. nubilalis egg predation rates for the three primary predators in sweet corn and to examine the impact of alternative foods on these predation rates. The long-range goal is to be able to refine pest management in sweet corn by including the expected contribution of predators as a factor in estimating damage from $O$. nubilalis.

\section{Materials and Methods}

No Choice Laboratory Predation. The potential maximum predation rates were determined for $C$. maculata adults and larvae, $H$. axyridis adults and larvae, and $O$. insidiosus adults and nymphs. C. maculata and $H$. axyridis adults and larvae from a laboratory colony were kept individually in 59-ml clear cups with three O. nubilalis egg masses placed on a piece of corn leaf. The $O$. nubilalis eggs were from a laboratory colony and had been laid within the $4 \mathrm{~d}$ immediately preceding the experiment. Egg mass consumption was recorded daily, and three egg masses were always kept in the cups to ensure that food was not limited. Partially consumed egg masses were recorded as $0.5 \mathrm{egg}$ masses eaten. The eggs and leaf were replaced every 2-3 d. The trial began with neonates (hatched within $24 \mathrm{~h}$ ) and adults (emerged within $72 \mathrm{~h}$ ) and continued until the insects died or immature insects emerged as adults. Death was determined by a lack of movement when probed with a brush. Because none of the $H$. axyridis neonates developed on $O$. nubilalis eggs, third and fourth instars were collected in the field to test if older instars could finish development on $O$. nubilalis eggs. O. insidiosus predation on $O$. nubilalis eggs was determined by keeping up to five adults or nymphs from a young field-collected colony in $30-\mathrm{ml}$ clear cups with two O. nubilalis egg masses. Eggs were replaced every 1-2 d, using a dissecting microscope to record the number of individual eggs consumed. For both the coccinellid and $O$. insidiosus trials, water was available from a moist paper towel placed in the bottom of the cup, and the insects were kept in rooms maintained at either $20^{\circ}$ or $27 \pm 1^{\circ} \mathrm{C}$ with a photoperiod of 16:8 (L:D) h. Table 1 contains the number of individuals and replicates for all species and growth stages in the trial.

Field Predation. The overall predation rate on $O$. nubilalis egg masses in combination with the population dynamics of predators and aphids was measured in the field. Four replicates of two treatments (predation and exclusion) were in plots of sweet corn seven rows wide (76-cm row spacing) and $4.6 \mathrm{~m}$ long. Four plantings, each with four replicates, were made at 2-wk intervals in a randomized complete block design, blocked by planting date at Cornell's Vegetable Research Farm in Geneva, NY, beginning on 12 May 1999. At first silk of each planting, fresh $O$. nubilalis egg masses from a laboratory colony were removed from the wax paper on which they were laid and directly pinned onto the bottom side of the corn leaves in both treatments. In the predation treatment, one $O$. nubilalis egg mass per plant was pinned through the midrib of the ear leaf of 100 plants in the interior five rows of the plot. In the exclusion treatment, one O. nubilalis egg mass per plant was pinned through the midrib of the ear leaf of 70 plants in the interior five rows. Each egg mass in the exclusion treatment was encircled with a 2-cm ring of "Pest Barrier" (Tanglefoot, Grand Rapids, MI), which was applied with a syringe to prevent access by crawling predators but still allow other factors to potentially remove the egg mass. This method of exclusion has previously been shown to be effective in excluding 
arthropod predators of Pieris rapae eggs in cabbage (Schmaedick and Shelton 1999). The pins were removed after $2 \mathrm{~d}$, and the number of pins that no longer had egg masses was recorded. Coccinellids and aphid populations were estimated by visually counting the insects on 25 consecutive plants in each plot before and after eggs were released. Sample collections were $1 \mathrm{wk}$ apart. The two counts were averaged together to estimate the mean coccinellid and aphid populations present while $O$. nubilalis egg predation was being monitored. $O$. insidiosus populations were not monitored in this experiment.

Field Cages. Field cages were used to understand which coccinellids were the most voracious predators of $O$. nubilalis eggs. This trial had five replications of four predator treatments in a complete randomized block design, blocked over time. The treatments were $40 \mathrm{H}$. axyridis larvae, $40 \mathrm{C}$. maculata adults, $40 \mathrm{C}$. maculata larvae, and a no predator control. All replications were conducted between 15 August and 13 September 2000. The field cages were plastic screen cages ( 50 squares $/ \mathrm{cm}^{2}$ mesh, 2.5 by 2.5 by $2.5 \mathrm{~m}$ cage size with a PVC frame), each placed over $\approx 30$ plants of sweet corn at Cornell's Vegetable Research Farm in Geneva, NY. The lower edges of the plastic netting were buried in the ground. All coccinellids and other large predators were manually removed from the cages before each predator release. Then $100 \mathrm{O} . \mathrm{nu}$ bilalis egg masses from a laboratory colony were pinned on the corn in each cage as in Field Predation, placing one egg mass per leaf on the leaves nearest the developing ear where the majority of $O$ nubilalis eggs are normally laid (Spangler and Calvin 2001). The egg mass density was based on coccinellid maximum egg consumption in the laboratory and exceeded typical field densities of $O$. nubilalis eggs. The predators used were collected in nearby corn fields and were released into the cages so that they were evenly distributed on the plants. Larvae were a mix of third and fourth instars. The predator densities used were similar to the maximum densities observed in sweet corn. H. axyridis adults were not tested based on data (see No Choice Laboratory Predation) that indicated that they fed very little on $O$. nubilalis eggs. After $2 \mathrm{~d}$, all the pins were removed from the plants, and the number of pins that no longer had $O$. nubilalis egg masses was recorded. The cages were moved as needed and rerandomized between replications so that the sweet corn in the field cages was always in the silk or blister stages. Only three replications could be completed with $H$. axyridis larvae because of a scarcity of larvae during the last two replications. In the plots containing the field cages, two sweet corn plants per plot from outside the field cages were destructively sampled each week to identify and estimate the aphids and other potential prey populations.

Laboratory Study on Food Alternatives. The impact of corn leaf aphids [Rhopalosiphum maidis (Fitch)], corn pollen and the combination of aphids and pollen on $O$. nubilalis egg predation was tested for adults and third instars of C. maculata, $H$. axyridis, and O. insidiosus. Using a completely randomized factorial design, seven predator treatments (including a control) and four diet treatments (28 total treatments) were tested with $20-26$ replications of each treatment. The predators were from colonies that were collected in agricultural fields and maintained in the laboratory for a maximum of four generations. Both coccinellid species were reared on $O$. nubilalis eggs, a meat diet described by Cohen (1985), and occasional aphids provided simultaneously. $O$. insidiosus were reared on O. nubilalis eggs and beans (Phaseolus vulgaris L.) infested with twospotted spider mites (Tetranychus urticae Koch). R. maidis were reared on barley (Hordeum vulgare L.) (Katsar and Gray 1999) from a population collected from sweet corn. All the predator populations had access to $O$. nubilalis eggs during rearing, so familiarity with this food source was similar for all predator populations and for all diet treatments. The testing arena was a $236-\mathrm{ml}$ waxed paper cup with a clear plastic lid. A piece of corn leaf, a moist paper towel, and one $O$. nubilalis egg mass were placed into each cup. The alternative food treatments were nothing, 50 R. maidis, $25 \mathrm{mg}$ corn pollen, and $50 \mathrm{R}$. maidis $+25 \mathrm{mg}$ corn pollen. A single insect was placed in this arena, and the cup was sealed with Parafilm M (American National Can, Chicago, IL) and placed in a rearing room with 16:8 (L:D) h at $20^{\circ} \mathrm{C}$ for $2 \mathrm{~d}$. Because $H$. axyridis adults frequently consumed all $50 \mathrm{R}$. maidis, 75 R. maidis were subsequently placed in cups with $H$. axyridis adults. After $2 \mathrm{~d}$, the number of consumed $O$. nubilalis eggs was recorded. Data were only recorded when the predator was alive at the end of the experiment.

Field Study on Food Alternatives. The same field cages described above were used to measure the influence of aphids or pollen on O. nubilalis egg predation by generalist predators. Because the screen mesh was too coarse to contain $O$. insidiosus, this trial was only conducted with the coccinellid predators. This experiment was designed as two separate factorial randomized complete blocks with five insect treatments (including a control) and two alternative food treatments in each. The insect treatments in both trials were 20 C. maculata adults, 20 C. maculata third instars, $20 \mathrm{H}$. axyridis third instars, 10 C. maculata third instars $+10 \mathrm{H}$. axyridis third instars, and a no predator control. The predators were collected from other corn fields and released so that they were uniformly distributed throughout the cage. The first trial compared a high aphid density $(\approx 250$ R. maidis per plant added) to a low aphid density (natural low aphid population), and the second trial compared normal pollen density during green silk stage to low pollen density (sweet corn manually detasseled before pollen shed). The variety 'Candy Corner' was used for both trials because it tends to have fewer aphids than other varieties (F.R.M., unpublished data). Aphids were transferred into the field cage by cutting aphid-infested leaves and emerging tassels from nearby heavily infested sweet corn plants (variety 'Cabaret') and tying them to the sweet corn plants inside the cage. The aphid trial was conducted before pollen was available, and the pollen trial was conducted in sweet corn with low aphid 


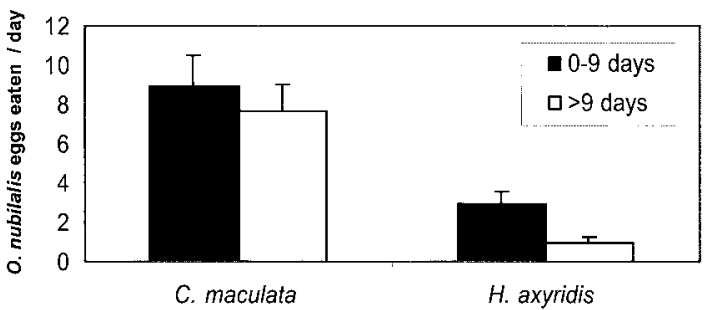

Fig. 1. Mean \pm SEM O. nubilalis egg mass consumption over time by adult coccinellids when no other food available. Data only from insects that lived at least $12 \mathrm{~d}$ at $20^{\circ} \mathrm{C}, 16: 8$ (L:D) h (C. maculata, $n=32 ; \mathrm{H}$. axyridis, $n=21$ ).

populations. In both trials, 20 O. nubilalis egg masses were pinned on the underside of sweet corn leaves near the developing shoot. Pins were retrieved $2 \mathrm{~d}$ later, and the number of pins without an egg mass was recorded. Twenty more fresh $O$. nubilalis egg masses were then pinned on the leaves, and the number of pins without an egg mass was recorded $2 \mathrm{~d}$ later $(4 \mathrm{~d}$ after predators were released). Egg mass density was similar to peak field densities (Spangler and Calvin 2000 ). Both trials were replicated twice with two predation estimates from each replication.

Data Analysis. In all studies, PROC MIXED (SAS Institute 1999) was used to compare treatments, using the residual maximum likelihood method. Least square means were used to compare treatment means. For the field study on food alternatives, repeated measures to account for the two egg releases with the same predators were included in the model. Significance was determined using $\alpha=0.05$, and differences between treatments were compared using Tukey's studentized range.

\section{Results}

No Choice Laboratory Predation. Harmonia axyridis adults ate significantly fewer $O$. nubilalis eggs than did C. maculata adults at $20^{\circ} \mathrm{C}(t=4.44 ; \mathrm{df}=73 ; P<$ $0.0001)$ and at $27^{\circ} \mathrm{C}(t=5.32 ; \mathrm{df}=76 ; P<0.0001$; Table $1)$. Not only did $H$. axyridis adults eat less than onehalf as many $O$. nubilalis eggs as C. maculata adults did, they avoided the eggs over time (Fig. 1). O. nubilalis egg consumption by $H$. axyridis adults decreased after the first $9 \mathrm{~d}(t=3.29 ; \mathrm{df}=21 ; P=0.0037)$, while $C$. maculata adults continued to eat $O$. nubilalis eggs at a constant rate $(t=1.16 ; \mathrm{df}=32 ; P=0.2556)$. There was no replication of growth chambers to statistically compare the effect of temperature, but the data indicate that adults consumed more eggs at $27^{\circ} \mathrm{C}$ than at $20^{\circ} \mathrm{C}$.

The larval results were different from the adult results in that consumption rates of $O$. nubilalis eggs by late $H$. axyridis and C. maculata instars were similar, and temperature did not seem to be a major factor (Table 1). That does not mean that $O$. nubilalis eggs were equally suitable for larvae of both species. Whereas C. maculata readily developed on O. nubilalis eggs, first instars of $H$. axyridis failed to develop, and larger field-collected larvae never molted or only

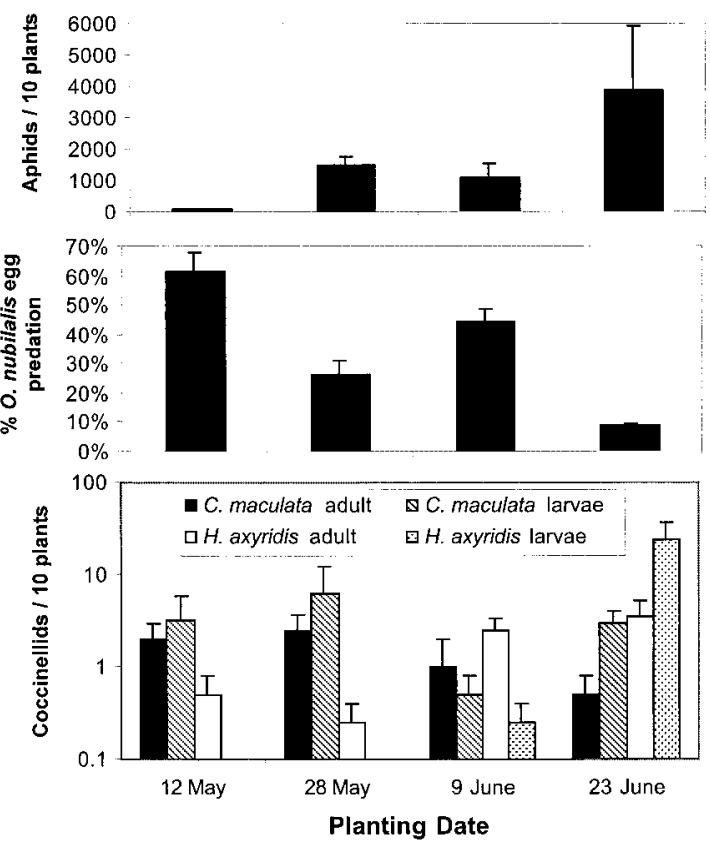

Fig. 2. Mean \pm SEM aphid populations, O. nubilalis egg predation rate $(2 \mathrm{~d})$, and coccinellid populations at green silk stage for sweet corn planted at four times in the season. Sentinel O. nubilalis eggs placed in the field 12 July, 26 July, 10 August, and 24 August for the four planting dates, respectively. Sweet corn sampled for aphids and coccinellids before and after egg placement, with 1 wk between sampling dates. Mean of the two sampling dates presented (Geneva, NY, 1999).

molted within the first $2 \mathrm{~d}$ after collection. The only $H$. axyridis to pupate were those that pupated within $2 \mathrm{~d}$ of collection. For both coccinellids at $20^{\circ} \mathrm{C}$, late instars consumed at least twice as many eggs as adults.

Orius insidiosus nymphs can complete development on $O$. nubilalis eggs (Table 1 ). While temperature effects cannot be statistically compared, developmental rate and egg consumption of nymphs were numerically greater at the warmer temperature, whereas the adults did not show a strong feeding response to warmer temperatures.

Field Predation. Egg losses in the control plots were always $<4 \%$, indicating that predation accounted for nearly all the missing eggs in this trial. Both aphid and overall coccinellid populations were highest in the last planting, but $O$. nubilalis egg predation rates were lowest in the last planting (Fig. 2). While O. insidiosus were not recorded in this trial, their population in sweet corn normally grows throughout the season (Musser 2003), so it is believed that the O. insidiosus population was also largest in the last planting when $O$. nubilalis egg predation was lowest. The negative correlation between aphid populations and $O$. nubilalis egg predation $(R=-0.95)$ provides a strong indication of the impact of aphids on predation rates of other insects in sweet corn.

Field Cages. After manually removing the predators, some predators still remained in the cages, re- 


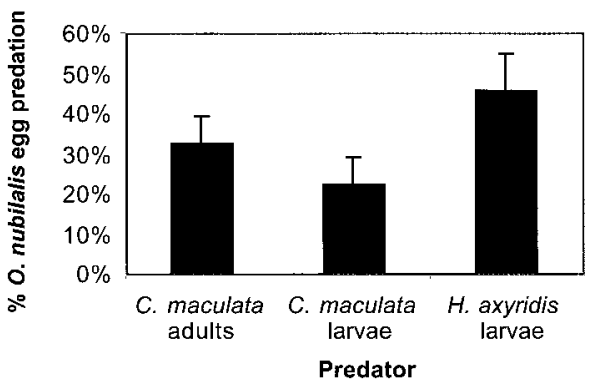

Fig. 3. Least square mean percent consumption \pm SEM of 100 O. nubilalis eggs by 40 coccinellids in field cages for $2 \mathrm{~d}$ corrected for control cage predation. There were no significant differences between coccinellid treatments.

sulting in some $O$. nubilalis egg predation in the control cages. Predation rates in the coccinellid cages were higher than predation rates in the control cages $(F=6.54 ; \mathrm{df}=3,10 ; P=0.0100)$. After applying Abbott's formula (Abbott 1925) to correct for control predation, there were no significant differences between $O$. nubilalis egg predation rates by $C$. maculata adults, $C$. maculata larvae, and $H$. axyridis larvae $(F=$ 1.97 ; $\mathrm{df}=2,6 ; P=0.2200)$, with an overall mean egg predation rate of $34 \%$ (Fig. 3 ). There were always $<20$ aphids per plant and little other potential prey in these cages, so available food for the coccinellids was mainly $O$. nubilalis eggs and sweet corn pollen.

Laboratory Study on Food Alternatives. Predation of $O$. nubilalis eggs by C. maculata adults and larvae and $O$. insidiosus nymphs was reduced when pollen and aphids were present (Fig. 4). Predation of $O$. nubilalis eggs was significantly reduced for $\mathrm{H}$. axyridis adults by aphids only. Whereas predation was numerically reduced when aphids and pollen were present in the $H$. axyridis larvae and $O$. insidiosus adult treatments, the differences were not statistically significant (H. axyridis larvae, $F=1.00 ; \mathrm{df}=3,99 ; P=0.3958 ; O$. insidiosus adults, $F=1.55 ; \mathrm{df}=3,97 ; P=0.2073)$. Although the pollen and/or aphids were never totally consumed, predation of $O$. nubilalis eggs by C. maculata adults and larvae was lower in the presence of corn pollen than in the presence of corn leaf aphids. Individually, egg predation in the $H$. axyridis adult and larva treatments was not statistically changed by the presence of pollen. However, when H. axyridis adult and larval data were combined for analysis, the difference in egg predation with and without pollen was significant $(t=2.22 ; \mathrm{df}=95 ; P=0.0287)$. When comparing mean egg predation by predators over all diets, representing the various situations found in the field, C. maculata adults and larvae consumed more eggs per insect than all other predators tested (Fig. 5).

Field Study on Food Alternatives. Although every effort was made to remove all predators from the field cages before releasing the $O$. nubilalis eggs, eggs in the control cages still experienced some predation, and the control predation level differed among the food treatments. Therefore, to compare egg predation among the insect and alternative food treatments, the predation levels were corrected for control predation in each alternative food treatment using Abbott's formula (Abbott 1925). Egg predation was lower in the presence of aphids for all treatments $(F=6.23$; $\mathrm{df}=$ $1,14 ; P=0.0256)$, but there were no significant differences between coccinellid treatments $(F=0.61$; $\mathrm{df}=3,8 ; P=0.6259 ;$ Fig. 6 ). In the trial comparing pollen with no pollen, there was no impact of corn pollen on egg predation $(F=1.10 ; \mathrm{df}=1,14 ; P=$ 0.3116 ), and $H$. axyridis larvae consumed marginally more $O$. nubilalis eggs than the other coccinellids $(F=$ $4.03 ; \mathrm{df}=3,8 ; P=0.0511)$. These results agree with the data shown in Field Cages, documenting that all the predators tested consume similar quantities of $O . n u$ bilalis eggs. There were no significant food by predator interactions in the field cage experiments for either aphid or pollen comparisons.

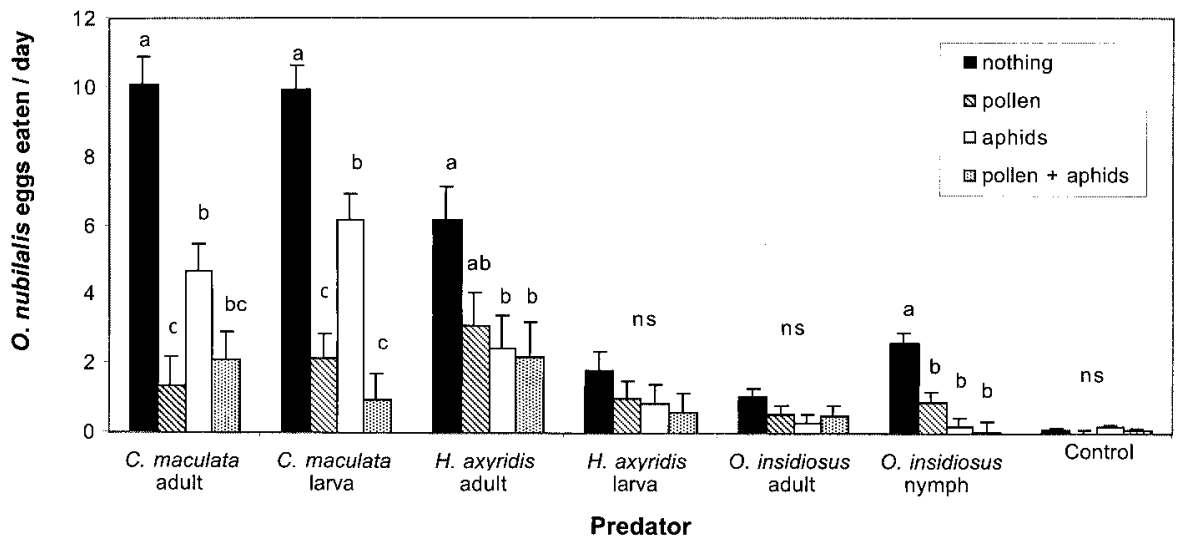

Fig. 4. Mean consumption of $O$. nubilalis eggs \pm SEM as affected by availability of alternative foods for the generalist predators C. maculata, H. axyridis, and O. insidiosus. Alternative foods were nothing, $25 \mathrm{mg}$ corn pollen, 50 aphids, and 25 mg corn pollen +50 aphids. Insects kept individually in cups at $20^{\circ} \mathrm{C}$ and 16:8 (L:D) h for 2 d. Letters show significant differences in egg predation between alternative foods within a species but not between species (Tukey, $\alpha=0.05)$. ns, not significant. 


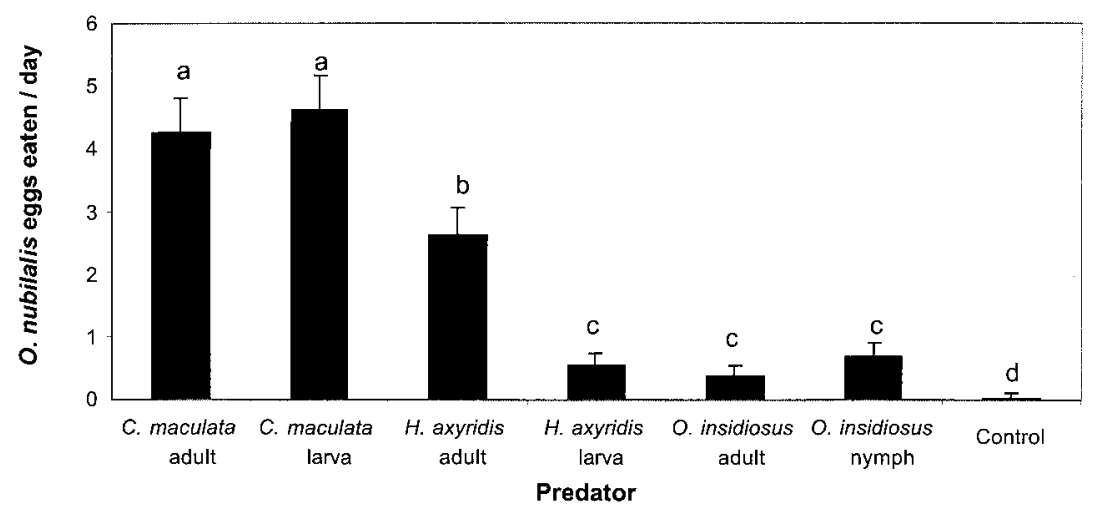

Fig. 5. Mean consumption of $O$. nubilalis eggs per day \pm SEM over four treatments with different alternative foods available. Insects were kept individually in cups at $20^{\circ} \mathrm{C}$ and 16:8 (L:D) h for $2 \mathrm{~d}$. Data transformed by square root for statistical analysis. Back-transformed data presented. Means with the same letter are not statistically different (Tukey, $\alpha=0.05)$.

\section{Discussion}

Adult and immature stages of the three major predators in sweet corn, C. maculata, H. axyridis, and $O$. insidiosus, all feed on $O$. nubilalis eggs. However, the voracity with which they consume $O$. nubilalis eggs varies by species, growth stage, and by the alternative foods available. In the laboratory under a variety of conditions, C. maculata adults and larvae generally consumed more $O$. nubilalis egg masses than did $H$. axyridis or $O$. insidiosus. This was likely a function of smaller overall food intake by $O$. insidiosus, but not for $H$. axyridis, because $H$. axyridis has been found to consume more pea aphids [Acyrthosiphon pisum (Harris) ] (Harmon et al. 1998) and corn leaf aphids (F.R.M., unpublished data) than does C. maculata. Therefore, larger populations of $O$. insidiosus and $H$. axyridis would be needed to consume the same number of $O$. nubilalis eggs as does C. maculata. As mean populations of $O$. insidiosus are approximately five times larger than mean C. maculata populations (Musser 2003), both species are expected to be important O. nubilalis egg predators. However, H. axyridis populations are somewhat smaller than C. maculata

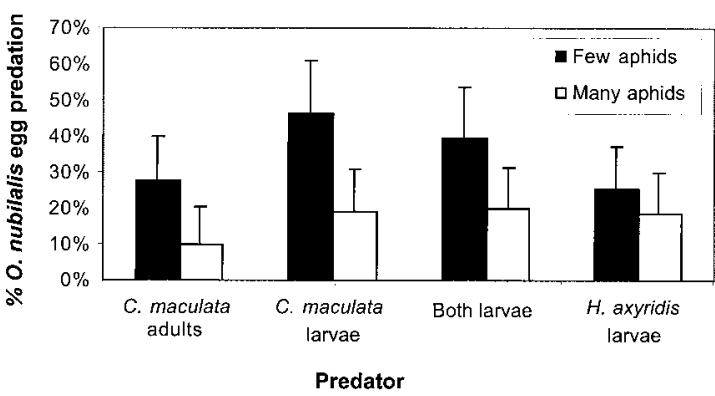

Fig. 6. Mean \pm SEM sentinel O. nubilalis egg predation corrected for egg predation in the control cages for aphid and no aphid treatments in 2.5 by 2.5 by 2.5 m field cages with 20 predators for $2 \mathrm{~d}$. Low aphids, natural aphid populations (<50/plant); high aphids, 250 aphids/plant added. populations in sweet corn, so the consumption of $O$. nubilalis eggs by $H$. axyridis is expected to be minor.

The role of alternative foods in biological control of $O$. nubilalis by generalist predators is complex. Based on predator monitoring data in sweet corn during 2000-2001 (Musser and Shelton 2003), C. maculata population growth is correlated to pollen availability, whereas $H$. axyridis population growth is correlated to aphid populations. Adult $O$. insidiosus densities are positively correlated to both pollen and aphids, whereas $O$. insidiosus nymph densities are not correlated to either food source (F.R.M., unpublished data). Positive numerical responses of generalist predators to the presence of abundant food sources have also been shown by others (Wright and Laing 1980, Hemptinne et al. 1992, Cottrell and Yeargan 1998). However, the data presented here and confirmed by others (Hazzard and Ferro 1991, Zheng 1992, Cottrell and Yeargan 1998), show that the consumption of $O$. nubilalis eggs per insect is lower when alternative foods are available. Therefore, overall biological control from generalist predators will be determined by the size of the numerical response increase associated with the presence of alternative foods in comparison with the decreased functional response. By combining the predator monitoring data mentioned above with the laboratory data shown in Fig. 4, it seems that, in sweet corn, the negative functional response more than compensates for the positive numerical response (F.R.M., unpublished data), resulting in somewhat decreased $O$. nubilalis egg predation when aphids and pollen are abundant. This is consistent with the results of our field predation study (Fig. 2).

Aphid populations in sweet corn that are available to predators are generally largest at green tassel stage, just before pollen shed (Wright and Laing 1980, F.R.M., unpublished data). O. nubilalis oviposition is also correlated to the growth stage of sweet corn, with peak oviposition generally occurring during silking, when pollen is readily available (Spangler and Calvin 2000). Spangler et al. (2003) also found that O. nubi- 
lalis eggs laid between green tassel and silking are those that are most strongly correlated to harvest damage. Therefore, the most critical control period, from a pest management perspective, is when aphids and pollen are most abundant and generalist predators are least effective.

The results of our field studies confirm that generalist predators can provide significant biological control against $O$. nubilalis. In addition, C. maculata and $O$. insidiosus are known to feed on the other major lepidopteran pests in sweet corn (Gross et al. 1985, Isenhour et al. 1989, Cottrell and Yeargan 1998), so the conservation of these natural pest control agents will have multiple positive impacts on pest management.

There are a number of ways in which this information about generalist predators can be potentially incorporated into the pest management decision-making process. For example, because corn pollen reduces $O$. nubilalis egg predation, it may be possible to breed varieties that shed less pollen, without sacrificing pollination, to enhance biological control. Similarly, because aphids stimulate oviposition by coccinellids but contribute to reduced $O$. nubilalis egg predation, an early high aphid population followed by aphid control by selective insecticides or pathogens may be another way to increase biological control of lepidopteran pests. It is not yet known which management strategies can be used to maximize naturally occurring biological control. However, by knowing the behavior of these generalist predators under a variety of situations, we can now better predict the amount of $O$. nubilalis egg predation from these predators. Combined with the use of selective control methods that are not toxic to the predators, O. nubilalis egg predation can eventually be incorporated into economic threshold calculations, potentially reducing the number of recommended insecticide applications.

\section{Acknowledgments}

The authors thank R. S. Boyd, Jr., P. Smereka, M. Musser, and W. Wilsey for assistance with data collection. J. Nyrop, M. Hoffmann, and two anonymous reviewers were helpful in revising earlier drafts of this manuscript. Partial funding for this project was provided by the Paul Chapman Fellowship from the Cornell University Department of Entomology at NYSAES and the New York State Integrated Pest Management Program.

\section{References Cited}

Abbott, W. S. 1925. A method of computing the effectiveness of an insecticide. J. Econ. Entomol. 18: 265-267.

Ables, J. R., S. L. Jones, and D. W. McCommas. 1978. Response of selected predator species to different densities of Aphis gossypii and Heliothis virescens eggs. Environ. Entomol. 7: 402-404.

Andow, D. A., and S. J. Risch. 1985. Predation in diversified agroecosystems: relations between a coccinellid predator Coleomegilla maculata and its food. J. Appl. Ecol. 22: 357-372.

Coderre, D., E. Lucas, and I. Gagne. 1995. The occurrence of Harmonia axyridis (Pallas) (Coleoptera: Coccinellidae) in Canada. Can. Entomol. 127: 609-611.
Cohen, A. C. 1985. Simple method for rearing the insect predator Geocoris punctipes (Heteroptera: Lygaeidae) on a meat diet. J. Econ. Entomol. 78: 1173-1175.

Coll, M., and D. G. Bottrell. 1992. Mortality of European corn borer larvae by natural enemies in different corn microhabitats. Biol. Control. 2: 95-103.

Corey, D., S. Kambhampati, and G. Wilde. 1988. Electrophoretic analysis of Orius insidiosus (Hemiptera: Anthocoridae) feeding habits in field corn. J. Kans. Entomol. Soc. 71: 11-17.

Cottrell, T. E., and K. V. Yeargan. 1998. Effect of pollen on Coleomegilla maculata (Coleoptera: Coccinellidae) population density, predation, and cannibalism in sweet corn. Environ. Entomol. 27: 1402-1410.

Elliott, N. C., R. W. Kieckhefer, and D. A. Beck. 2000. Adult coccinellid activity and predation on aphids in spring cereals. Biol. Control. 17: 218-226.

Eubanks, M. D., and R. F. Denno. 2000. Health food versus fast food: The effects of prey quality and mobility on prey selection by a generalist predator and indirect interactions among prey species. Ecol. Entomol. 25: 140-146.

Flood, B., R. Foster, and B. Hutchison. 1995. Sweet corn, pp. 19-40. In R. Foster and B. Flood (eds.) Vegetable insect management with emphasis on the Midwest. Meister Publishing Company, Willoughby, $\mathrm{OH}$.

Giroux, S., R. M. Duchesne, and D. Coderre. 1995. Predation of Leptinotarsa decemlineata (Coleoptera: Chrysomelidae) by Coleomegilla maculata (Coleoptera: Coccinellidae): comparative effectiveness of predator developmental stages and effect of temperature. Environ. Entomol. 24: 748-754.

Gross, H. R., Jr., S. D. Pair, and R. D. Jackson. 1985. Behavioral responses of primary entomophagous predators to larval homogenates of Heliothis zea and Spodoptera frugiperda (Lepidoptera: Noctuidae) in whorl-stage corn. Environ. Entomol. 14: 360-364.

Harmon, J. P., J. E. Losey, and A. R. Ives. 1998. The role of vision and color in the close proximity foraging behavior of four coccinellid species. Oecologia (Heidelb). 115: 287-292.

Hazzard, R. V., and D. N. Ferro. 1991. Feeding responses of adult Coleomegilla maculata (Coleoptera: Coccinellidae) to eggs of Colorado potato beetle (Coleoptera: Chrysomelidae) and green peach aphids (Homoptera: Aphididae). Environ. Entomol. 20: 644-655

Hemptinne, J. L., A.F.G. Dixon, and J. Coffin. 1992. Attack strategy of ladybird beetles (Coccinellidae): Factors shaping their numerical response. Oecologia (Heidelb). 90: $238-245$.

Hironori, Y., and S. Katsuhiro. 1997. Cannibalism and interspecific predation in two predatory ladybirds in relation to prey abundance in the field. Entomophaga. 42: 153-163.

Hoffmann, M. P., M. S. Orfanedes, L. H. Pedersen, J. J. Kirkwyland, E. R. Hoebeke, and R. Ayyappath. 1997. Survey of lady beetles (Coleoptera: Coccinellidae) in sweet corn using yellow sticky cards. J. Entomol. Sci. 32: $358-369$.

Hudon, M., and E. J. LeRoux. 1986. Biology and population dynamics of the European corn borer (Ostrinia nubilalis) with special reference to sweet corn in Quebec. III. Population dynamics and spatial distribution. Phytoprotection. 67: 93-115.

Isenhour, D. J., B. R. Wiseman, and R. C. Layton. 1989. Enhanced predation by Orius insidiosus (Hemiptera: Anthocoridae) on larvae of Heliothis zea and Spodoptera frugiperda (Lepidoptera: Noctuidae) caused by prey 
feeding on resistant corn genotypes. Environ. Entomol. 18: $418-422$

Katsar, C., and S. Gray. 1999. Rearing aphids to use in virusvectors studies, pp. 181-195. In K. Maramorosch and F. Mahmood (eds.) Maintenance of human, animal, and plant pathogen vectors. Science Publishers, Inc., Enfield, $\mathrm{NH}$.

Musser, F. R. 2003. The impact of naturally occurring predators and selective insecticidal products on Ostrinia $\mathrm{nu}$ bilalis management in sweet corn. PhD dissertation, Cornell University, Ithaca, NY.

Musser, F. R., and A. M. Shelton. 2003. Factors altering the temporal and within-plant distribution of coccinellids in corn and their impact on potential intra-guild predation. Environ. Entomol. 32: 575-583.

Phoofolo, M. W., J. J. Obrycki, and L. C. Lewis. 2001. Quantitative assessment of biotic mortality factors of the European corn borer (Lepidoptera: Crambidae) in field corn. J. Econ. Entomol. 94: 617-622.

Putnam, W. L. 1964. Occurrence and food of some coccinellids (Coleoptera) in Ontario peach orchards. Can. Entomol. 96: 1149-1155.

Roger, C., D. Coderre, C. Vigneault, and G. Boivin. 2001. Prey discrimination by a generalist coccinellid predator: effect of prey age or parasitism? Ecol. Entomol 26: 163172.

SAS Institute. 1999. SAS/STAT user's guide, version 8. SAS Institute, Cary, NC.

Schmaedick, M. A., and A. M. Shelton. 1999. Experimental evaluation of arthropod predation on Pieris rapae (Lepidoptera: Pieridae) eggs and larvae in cabbage. Environ. Entomol. 28: 439-444.
Spangler, S. M., and D. D. Calvin. 2000. Influence of sweet corn growth stages on European corn borer (Lepidoptera: Crambidae) oviposition. Environ. Entomol. 29: $1226-1235$.

Spangler, S. M., and D. D. Calvin. 2001. Vertical distribution of European corn borer (Lepidoptera: Crambidae) egg masses on sweet corn. Environ. Entomol. 30: 274-279.

Spangler, S. M., D. D. Calvin, and M. A. Nemeth. 2003. Infestation of European corn borer (Lepidoptera: Crambidae) in sweet corn as predicted by time of oviposition. J. Econ. Entomol. 96: 413-419.

Wheeler, A. G., Jr., and C. A. Stoops. 1996. Status and spread of the Palearctic lady beetles Hippodamia variegata and Propylea quatuordecimpunctata (Coleoptera: Coccinellidae) in Pennsylvania, 1993-1995. Entomol. News. 107: 291-298.

Whitman, R. J. 1975. Natural control of European corn borer, Ostrinia nubilalis (Hübner) in New York. PhD dissertation, Cornell University, Ithaca, NY.

Wright, E. J., and J. E. Laing. 1980. Numerical response of coccinellids to aphids in corn in southern Ontario. Can. Entomol. 112: 977-988.

Zheng, T. 1992. Functional response of Coleomegilla maculata (Degeer) (Coleoptera: Coccinellidae) on eggs of European Corn Borer, Ostrinia nubilalis (Hübner) (Lepidoptera: Pyralidae). MS thesis, University of Delaware, Newark, DE.

Received for publication 28 February 2003; accepted 4 August 2003 